\title{
Analisis Kelayakan Pemukiman Menggunakan Metode Analytic Hierarchy Process (AHP) Kecamatan Kuta Baro, Kabupaten Aceh Besar
}

\author{
Akmal Muhni*, Eli Rahmayani, Dewi Sartika \\ Program Studi Teknik Geologi, Fakultas Teknik, Universitas Syiah Kuala \\ *Co-Author:akmalmuhni@unsyiah.ac.id
}

\begin{abstract}
.
The use of land resources for settlements is generally determined by the capability of the land or the appropriateness of the land. Residential area planning must consider the risk of a disaster because it will have an impact on material and physical losses. Administratively, the research area is located in the north of Kuta Baro Sub-District, Aceh Besar District, Aceh Province with a research area of about $12 \mathrm{~km}^{2}$. The research location which is close to the Seulawah Agam volcano will cause potential impacts of disasters such as volcanic eruption and landslide. The purpose of analyzing settlement land use using the Analytic Hierarchy Process (AHP) method in this study is to determine and analyze the feasibility of residential land at the research location. The parameters used in the land use analysis consist of 5 parameters including rock lithology, geomorphological conditions, slope, soil type, and rainfall. The results obtained in this study were 3 (three) classes of land use feasibility zones, namely the feasible zone, the less feasible zone, and the unfeasible zone. Analysis of land use suitability based on the feasible zone for settlements in Kuta Baro District with lowland geomorphology (0 - 8\% slope level), rock lithology in the form of silt deposits, low rainfall, and alluvium soil types which have a very low level of erosion.
\end{abstract}

Keyword : Settlement, Analytical Hierarchy Process, feasibility

\section{PENDAHULUAN}

Kecamatan Kuta Baro merupakan salah satu kecamatan yang terletak di Kabupaten Aceh Besar dengan luas daerah mencapai $61,07 \mathrm{~km}^{2}$ [1]. Luas daerah yang dipetakan adalah sekitar $12 \mathrm{~km}^{2}$ yang terdiri dari dataran rendah, perbukitan rendah hingga perbukitan. Lokasi penelitian yang didominasi oleh topografi curam hingga sangat curam menyebabkan lokasi ini memiliki tingkat rawan longsor yang cukup tinggi. Oleh karena itu, penelitian ini dilakukan untuk mengetahui apakah lokasi penelitian termasuk kedalam kategori sesuai untuk dijadikan pemukiman atau tidak. Penyebab terjadinya suatu masalah pada suatu wilayah atau daerah bisa disebabkan karena lahan yang digunakan tidak sesuai dengan rencana penggunaan yang telah ditentukan. Salah satu penyebabnya adalah karena keseimbangan ekologi yang tidak diperhatikan. Agar penggunaan lahan menjadi efisien dan efektif, maka perlu dilakukan usaha pemanfaatan lahan untuk ditata dengan baik sehingga bisa mengatasi keterbatasan lahan yang ada [2].

Evaluasi penggunaan lahan dilakukan menggunakan parameter yang dianalisis dengan melakukan pembobotan nilai pada tiap parameternya. Adapun parameter yang digunakan pada penelitian ini terdiri dari 5 antara lain litologi batuan, geomorfologi, kemiringan lereng, jenis tanah dan curah hujan pada lokasi penelitian. Interpretasi batuan berdasarkan karakteristik fisik batuan yang ada seperti ukuran butir, komposisi, dan warna [3]. Bentang lahan yang dijadikan pertimbangan untuk digunakan sebagai lahan pemukiman adalah daerah yang mudah mendapatkan air, daerah yang relatif datar, dan daerah yang aman dari banjir [4].

Kelima parameter tersebut diperoleh dari hasil pemetaan geologi pada lokasi penelitian dan data sekunder yang selanjutnya dianalisis menggunakan metode Analytic Hierarchy Proses (AHP). Metode Analytic Hierarchy Proses (AHP) dilakukan dengan melakukan pembobotan nilai berdasarkan tingkat kepentingan yang dimiliki tiap parameter [5]. Setelah didapatkan nilai akhir dari tiap parameter selanjutnya dilakukan pembuatan peta rekomendasi penggunaan lahan untuk pemukiman dengan menggunakan Software ArcGis. Setiap parameter yang sudah dilakukan penghitungan selanjutnya dilakukan proses tumpang tindih bobot (overlay).

\section{METODE PENELITIAN}

Metode Analytic Hierarchy Process (AHP) dengan pembobotan nilai dilakukan dengan merujuk kepada Tabel 1 mengenai tingkat kepentingan pembobotan perameter. Pembobotan nilai tersebut didapatkan dari hasil perbandingan antara parameter satu dengan yang lainnya. Pemetaan geologi yang dilakukan pada penelitian ini berguna untuk memperoleh data primer. Data primer tersebut terdiri dari kondisi litologi, geomorfologi, dan jenis tanah.

Tahapan yang pertama kali dilakukan adalah menyusun tingkat hirarki tiap kriteria yang digunakan sebagai parameter. Setelah dilakukan penyusunan tingkat hirarki, tahapan yang dilakukan selanjutnya adalah melakukan penghitungan tingkat 
kepentingan parameter yang digunakan. Setelah didapatkan nilai tiap parameternya, maka proses selanjutnya yang dilakukan adalah melakukan metode tumpang tindih antar peta hasil yang diperoleh dari hasil pengolahan dari tiap parameter yang ada.

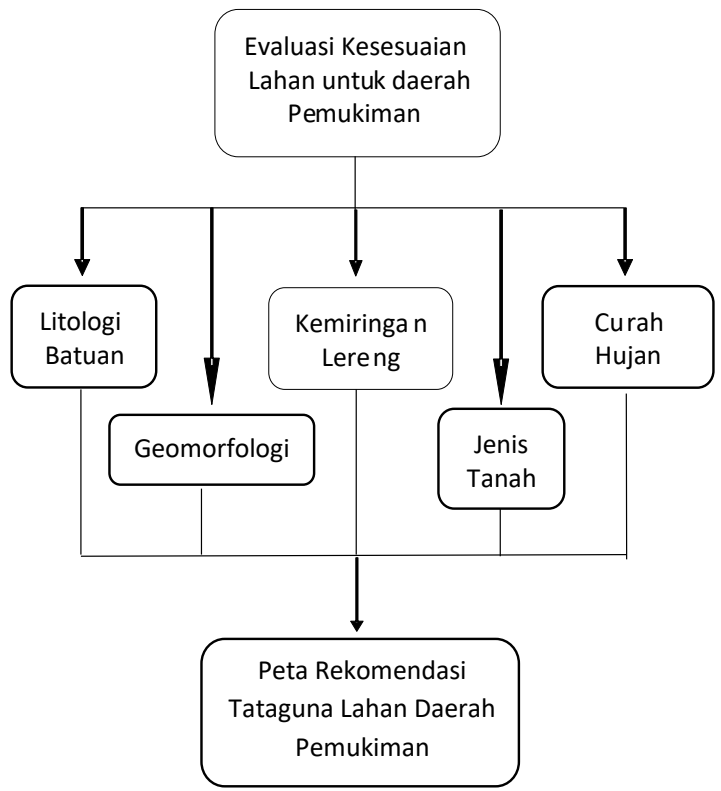

Gambar 1. Penyusunan Hirarki pada metode AHP dimodifikasi dari Saaty, 1980 [6]

Setelah tahapan Analytic Hierarchy Process (AHP) selesai dilakukan, selanjutnya dilakukan pengolahan lebih lanjut pada sistem informasi geografis dengan melakukan proses tumpang tindih dengan menggunukan metode intersect. Adapun tahapan yang dilakukan adalah sebagai berikut: Pada tahapan awal dilakukan pembobotan nilai pada tiap parameter dengan memberikan bobot nilai berdasarkan tingkat kepentingan yang dimiliki parameter yang ada.

Tabel 1. Pemberian nilai pada parameter

\begin{tabular}{cc}
\hline Parameter & Nilai \\
\hline Kemiringan Lereng & 1 \\
Litologi & 3 \\
Jenis Tanah & 5 \\
Morfologi & 7 \\
Curah Hujan & 9 \\
\hline
\end{tabular}

Selanjutnya dibuat tabel dari hasil penilaian tersebut untuk dilakukan perbandingan antar parameter atau matriks pairwise comparison. Setelah dibuat tabel maka akan didapatkan hasil dari perbandingan antar parameter. Selanjutnya dilakukan penjumlahan hasil perbandingan tiap kolom yang ada. Setelah mendapat total dari penjumlahan tiap parameter, hasil dari perbandingan dibagi dengan total parameter dan dihitung rata-rata nilai perbaris. Nilai rata-rata ini dijadikan sebagai nilai Matrix A. Selanjutnya nilai tiap baris parameter dijumlahkan untuk mendapatkan nilai Matrix AX. Dimana Matrix AX ini digunakan untuk menghitung skor atau nilai tiap parameter pada saat proses pengolahan peta pada Software ArcGis.

Tabel 2. Matriks perbandingan antar parameter

\begin{tabular}{cccccc}
\hline & & & & & \\
& Kemiringan lereng & Litologi Batuan & Jenis Tanah & Morfologi & Curah Hujan \\
& & & & & $1: 9$ \\
\hline Kemiringan lereng & $1: 1$ & $1: 3$ & $1: 5$ & $1: 7$ & $3: 9$ \\
Litologi Batuan & $3: 1$ & $3: 3$ & $3: 5$ & $3: 7$ & $5: 9$ \\
Jenis Tanah & $5: 1$ & $5: 3$ & $5: 5$ & $5: 7$ & $7: 9$ \\
Morfologi & $7: 1$ & $7: 3$ & $7: 5$ & $7: 7$ & \\
\hline
\end{tabular}




\begin{tabular}{cccccc}
\hline Curah Hujan & $9: 1$ & $9: 3$ & $9: 5$ & $9: 7$ & $9: 9$ \\
\hline & & & & \\
& Tabel 3. Penjumlahan hasil perbandingan parameter & \\
& & & & & \\
& Kemiringan lereng & Litologi Batuan & Jenis Tanah & Morfologi & Curah Hujan \\
& & & & & \\
\hline Kemiringan lereng & 1 & 0.33 & 0.2 & 0.14 & 0.11 \\
Litologi Batuan & 3 & 1 & 0.6 & 0.42 & 0.33 \\
Jenis Tanah & 5 & 1.66 & 1 & 0.71 & 0.55 \\
Morfologi & 7 & 2.33 & 1.4 & 1 & 0.77 \\
Curah Hujan & 9 & 3 & 1.8 & 1.28 & 1 \\
Total & 25 & 8.32 & 5 & 3.55 & 2.76 \\
\hline
\end{tabular}

Tabel 4. Pembagian bobot perbandingan parameter dengan total parameter

\begin{tabular}{ccccccc}
\hline & & & & & & \\
& Kemiringan lereng & Litologi Batuan & Jenis Tanah & Morfologi & Curah Hujan & AVERAGE \\
& & & & & & \\
\hline Kemiringan lereng & 0.04 & 0.0396635 & 0.04 & 0.0394366 & 0.0398551 & 0.039791 \\
Litologi Batuan & 0.12 & 0.1201923 & 0.12 & 0.1183099 & 0.1195652 & 0.1196135 \\
Jenis Tanah & 0.2 & 0.1995192 & 0.2 & 0.2 & 0.1992754 & 0.1997589 \\
Morfologi & 0.28 & 0.2800481 & 0.28 & 0.2816901 & 0.2789855 & 0.2801447 \\
Curah Hujan & 0.36 & 0.3605769 & 0.36 & 0.3605634 & 0.3623188 & 0.3606918 \\
Total & 1 & 1 & 1 & 1 & 1 & 1 \\
\hline
\end{tabular}

Tabel 5. Penghitungan Matrix AX

\begin{tabular}{ccccccc}
\hline & & & & & & \\
& Kemiringan lereng & Litologi Batuan & Jenis Tanah & Morfologi & Curah Hujan & MATRIX AX \\
& & & & & & \\
\hline Kemiringan lereng & 0.04 & 0.0396635 & 0.04 & 0.0394366 & 0.0398551 & 0.198955154 \\
Litologi Batuan & 0.12 & 0.1201923 & 0.12 & 0.1183099 & 0.1195652 & 0.598067384 \\
Jenis Tanah & 0.2 & 0.1995192 & 0.2 & 0.2 & 0.1992754 & 0.998794593 \\
Morfologi & 0.28 & 0.2800481 & 0.28 & 0.2816901 & 0.2789855 & 1.400723725 \\
Curah Hujan & 0.36 & 0.3605769 & 0.36 & 0.3605634 & 0.3623188 & 1.803459144 \\
\hline
\end{tabular}

Tabel 6. Penghitungan nilai Eigen Max Valeu

\begin{tabular}{cccc}
\hline & Matrix AX & Matrix X & $\lambda \max$ \\
\hline Kemiringan lereng & 0.2 & 0.04 & 5.00 \\
Litologi Batuan & 0.5 & 0.1 & 5.00 \\
Jenis Tanah & 1 & 0.2 & 5.00 \\
Morfologi & 1.4 & 0.28 & 5.00 \\
Curah Hujan & 1.8 & 0.36 & 5.00 \\
Average & & & 5.00 \\
IK & & & 0.00 \\
RK & & 0 \\
\hline
\end{tabular}

Jika nilai dari rasio konsistensi yang diperoleh kurang dari 0.1 maka nilai bobot tingkat kepentingan parameter yang digunakan rasio konsistensi penelitian ini cukup konsisten sehingga dapat dipertanggung jawabkan. Penghitungan nilai tingkat kepentingan parameter juga dilakukan pada kelas-kelas yang terdapat pada parameter yang digunakan. Ini dilakukan untuk mendapatkan nilai skor akhir pada pembobotan untuk dilakukan penghitungan dan pengolahan data untuk di overlay menggunakan metode intersect pada sistem informasi geografis (SIG). Evaluasi kesesuaian lahan bisa dilakukan dengan membandingkan kualitas dan karakteristik yang dimiliki oleh lahan yang ada dengan persyaratan penggunaan lahan, hasil dari perbandingan yang didapatkan akan menunjukkan kesesuaian kelas untuk penggunaan lahan yang diinginkan [7]. 
Dari hasil penghitungan nilai AHP pada tiap-tiap kriteria parameter yang digunakan, selanjutnya nilai ini dapat dimasukkan kedalam attribute peta tiap-tiap parameter yang berbentuk polygon (shapefile). Pada tiap parameter dilakukan perkalian nilai Matrix AX dan Matrix X untuk mendapatkan skor dari parameter tersebut. Setelah mendapatkan skor tiap parameter lalu dilakukan proses tumpang tindih dengan menggunakan metode intersect. Pada metode ini polygon peta yang memiliki nilai skor digabungkan menjadi satu melalui proses overlay. Setelah itu akan didapatkan zona sesuai, kurang sesuai dan tidak sesuai untuk dijadikan daerah pemukiman.

\section{HASIL DAN PEMBAHASAN}

Hasil analisis tata guna lahan untuk kawasan pemukiman Daerah Kuta Baro yang ada pada lokasi penelitian dengan menggunakan metode Analytic Hierarchy Process (AHP) dan dilakukan pengolahan menjadi data polygon (shapefile) menggunakan sistem informasi geografis (SIG). Terdapat 5 parameter yang digunakan yaitu litologi batuan, bentang alam, kemiringan lereng, jenis tanah, dan intensitas curah hujan, sebagai berikut:

\section{1) Kondisi Litologi}

Korelasi peta geologi regional [8] dengan kondisi litologi berdasarkan ciri-ciri endapan jatuhan piroklastik [9][10] yang terdapat pada lokasi penelitian terdiri dari 4 satuan batuan yaitu: tuff aliran piroklastik, tuff lapilli piroklastik, dan batuan beku andesit, serta endapan alluvial. Tuff jatuhan piroklastik, tuff lapilli piroklastik dan beku andesit memiliki kegunaan yang bisa dimanfaatkan sebagai bahan bangunan. Untuk evaluasi lahan daerah pemukiman urutan nilai yang diberikan dari yang tertinggi hingga terendah adalah tuff aliran piroklastik, tuff lapilli piroklastik, endapan aluvial, dan batuan beku andesit. Peta litologi lokasi penelitian dapat dilihat pada gambar 2.

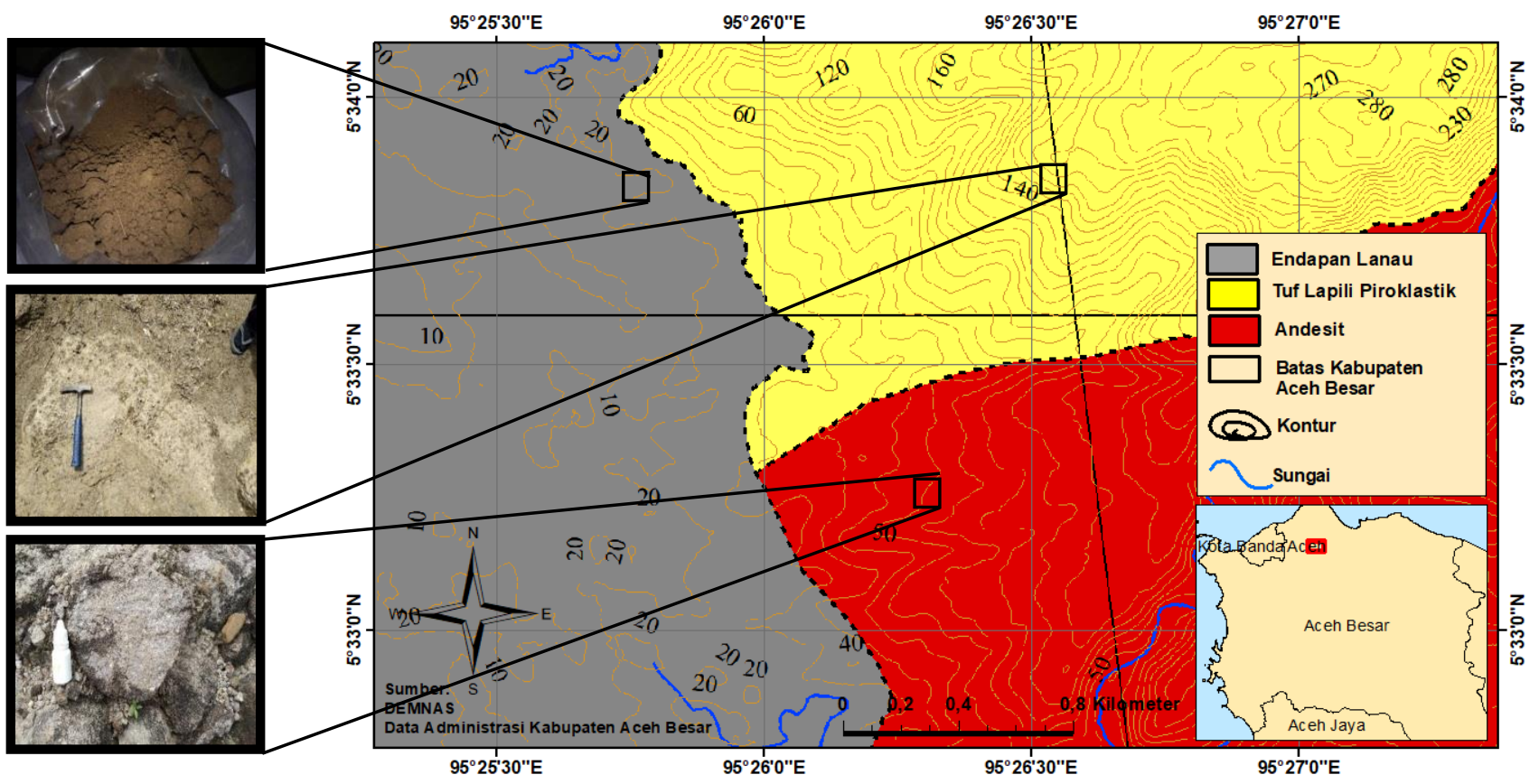

Gambar 2. Peta Litologi Lokasi Penelitian

\section{2) Geomorfologi}

Berdasarkan pengamatan yang telah dilakukan pada lokasi penelitian, didapatkan hasil kondisi geomorfologi terdiri dari 3 (tiga) satuan geomorfologi yaitu dataran rendah, perbukitan rendah, dan perbukitan [11]. Pada proses pemberian nilai pembobotan AHP, daerah morfologi dataran rendah, diberi nilai lebih tinggi dari yang lainnya karena memiliki topografi datar hingga landai dengan tingkat terjadinya erosi sangat kecil. Selanjutnya, Berdasarkan Klasifikasi Van Zuidam (1985) bahwa untuk daerah morfologi perbukitan rendah diberi nilai lebih kecil dari dataran rendah karena tingkat terjadinya erosi sedang, dimana kemiringan lereng pada daerah ini adalah curam- agak curam. Sedangkan untuk daerah perbukitan, topografi yang dimiliki adalah curam dengan kemiringan lereng berada pada curam sampai dengan sangat curam. Erosi pada morfologi ini terjadi pada lereng yang curam. 


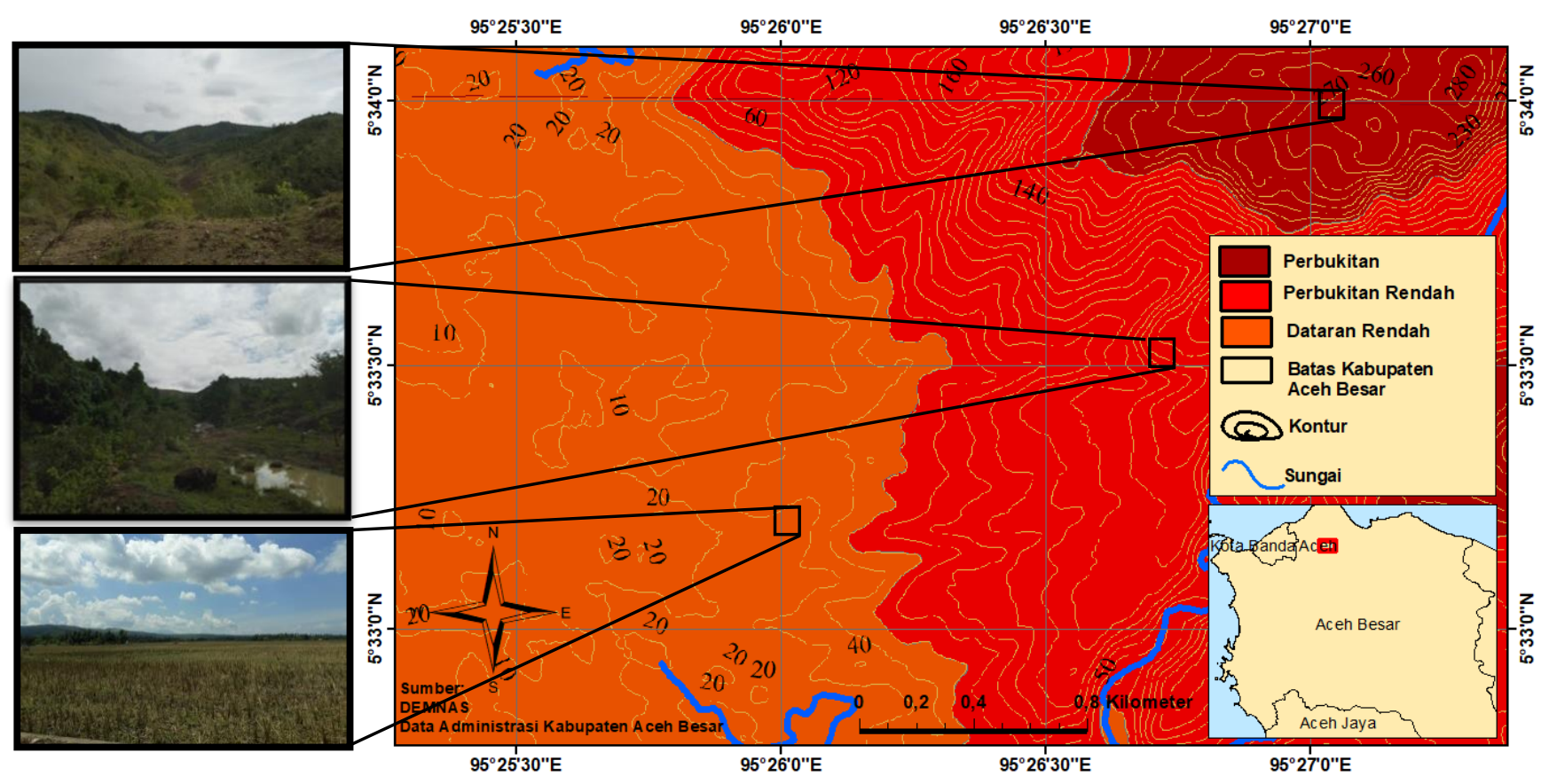

Gambar 3. Peta Geomorfologi Lokasi Penelitian

\section{3) Kemiringan Lereng}

Lereng merupakan salah satu pembatas penggunaan lahan. Berdasarkan peta kemiringan lereng yang telah dibuat (gambar 4), dapat diketahui bawah tingkat kemiringan lereng pada lokasi penelitian adalah dari $0 \%$ hingga $>45 \%$ dimana kemiringan lereng dari datar sampai curam. Ketinggian atau elevasi juga merupakan salah satu faktor yang dijadikan acuan untuk penggunaan lahan. Daerah yang memiliki kemiringan lereng $0-8 \%$ meter merupakan daerah yang baik untuk pemukiman karena memiliki kemiringan lereng yang datar hingga landai dan potensi terjadinya erosi sangat sedikit. Sedangkan daerah dengan kemiringan lereng 8 hingga $>45 \%$ merupakan daerah yang bisa digunakan untuk lahan pertanian dan perkebunan.

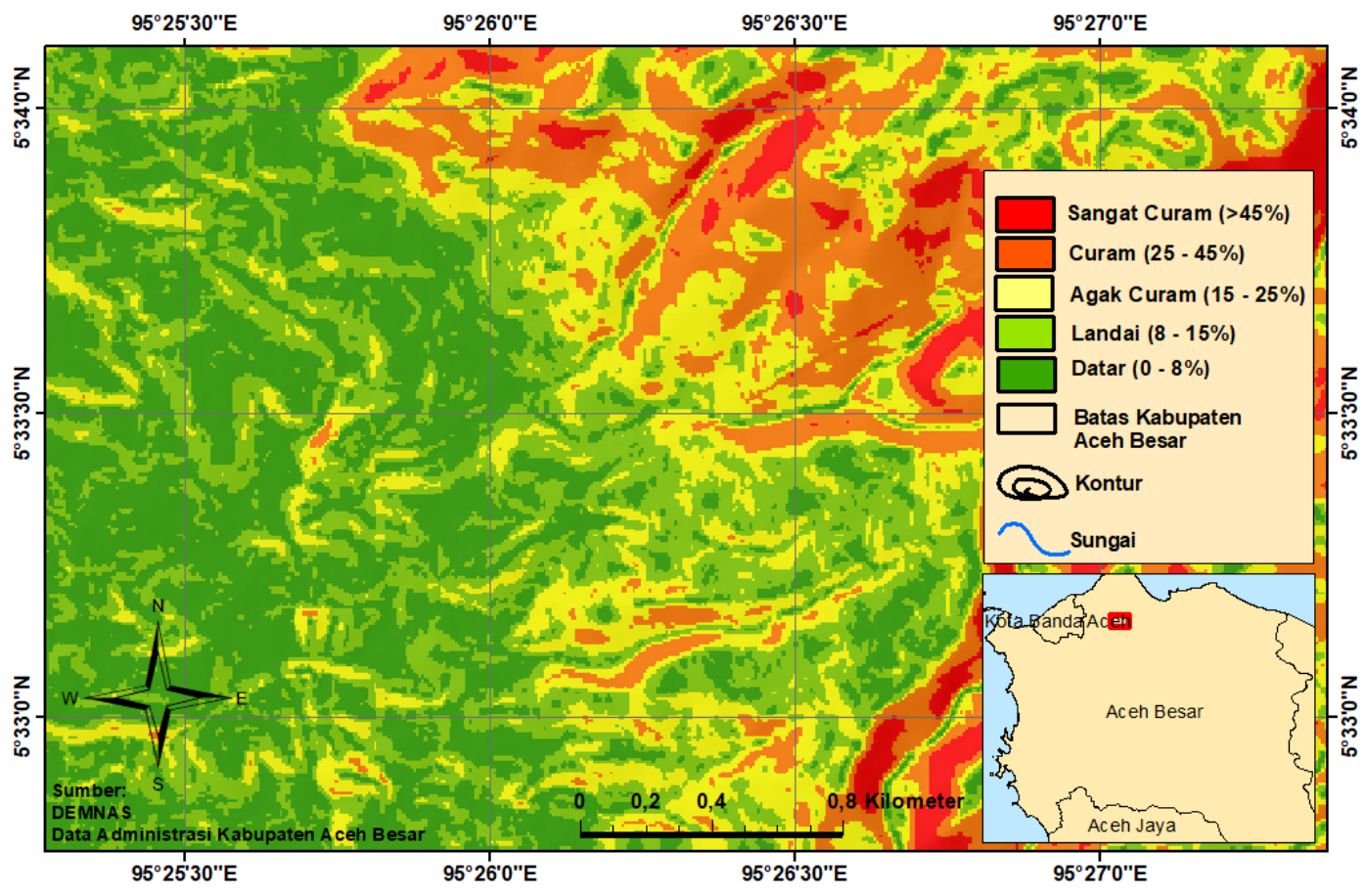

Gambar 4. Peta Persentase Kemiringan Lereng Lokasi Penelitian 
Namun pada lereng yang agak curam hingga sangat curam harus memperhatikan unsur hara yang ada pada tanah jika dipergunakan untuk perkebunan. Serta untuk perencanaan lahan perkebunan pada daerah tersebut juga harus memperhatikan ketersedian air yang minim dengan membuat kolam penampung air untuk menjaga ketersedian air pada musim kemarau.

\section{4) Jenis Tanah}

Berdasarkan hasil penelitian yang telah dilakukan, terdapat 3 (tiga) jenis tanah pada lokasi penelitian yaitu tanah alluvial, litosol, dan grumusol. Tanah litosol merupakan Tanah yang terbentuk dari pelapukan batuan beku dan batuan sedimen. Tanah litosol termasuk kedalam tanah yang masih muda dan sedang berkembang, bertekstur kasar hingga halus. Sedangkan tanah grumusol merupakan Tanah yang terbentuk dari pelapukan batuan kapur dan tuffa vulkanik, berwarna hitam dan bertekstur kering. Sesuai dengan SK Mentan 837/KTPS/UM/11/1980 mengenai kriteria jenis tanah berdasarkan kepekaan terhadap erosi diketahui bahwa tanah alluvial memiliki tingkat kepekaan yang sangat rendah, sedangkan tanah litosol sangat peka terhadap erosi, dan tanah grumusol peka terhadap erosi. Berdasarkan tingkat kepekaan terhadap erosi dari tiap jenis tanah yang ada, semakin kecil tingkat kepekaannya maka semakin cocok untuk dijadikan pemukiman.

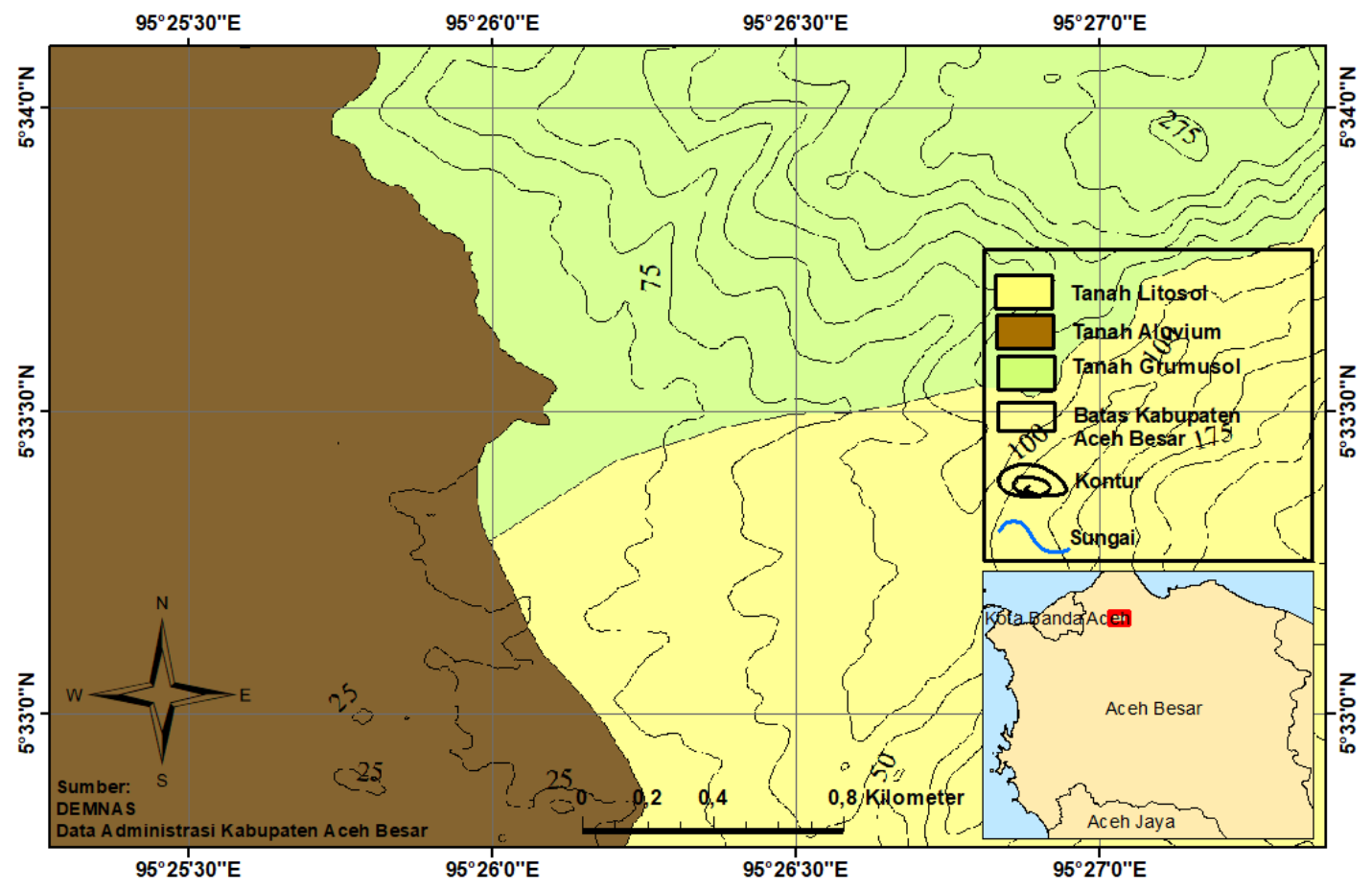

Gambar 5. Peta Jenis Tanah Lokasi Penelitian

\section{5) Curah Hujan}

Data curah hujan pada lokasi penelitian diperoleh dari 5 stasiun pengamatan yang terdapat pada lokasi penelitian, yaitu stasiun Kuta Baro, stasiun Sultan Iskandar Muda, stasiun Darussalam, stasiun Baitussalam dan stasiun Mesjid Raya. Pada lokasi penelitian intensitas hujan yang turun sangat rendah karena dalam setahun curah hujan yang terjadi kurang dari 1000 mm. Pada tiap tahunnya dari bulan Januari hingga Agustus curah hujan yang terjadi pada lokasi penelitian sangat rendah. Sedangkan pada bulan September hingga Desember curah hujan yang turun termasuk kedalam skala sedang. Hal ini terjadi selama 5 tahun terakhir berdasarkan data yang diperoleh dari BMKG Indrapuri, Kabupaten Aceh Besar Provinsi Aceh. Data grafik 5 tahun terakhir dapat dilihat pada peta curah hujan lokasi penelitian dapat dilihat pada gambar 6. 


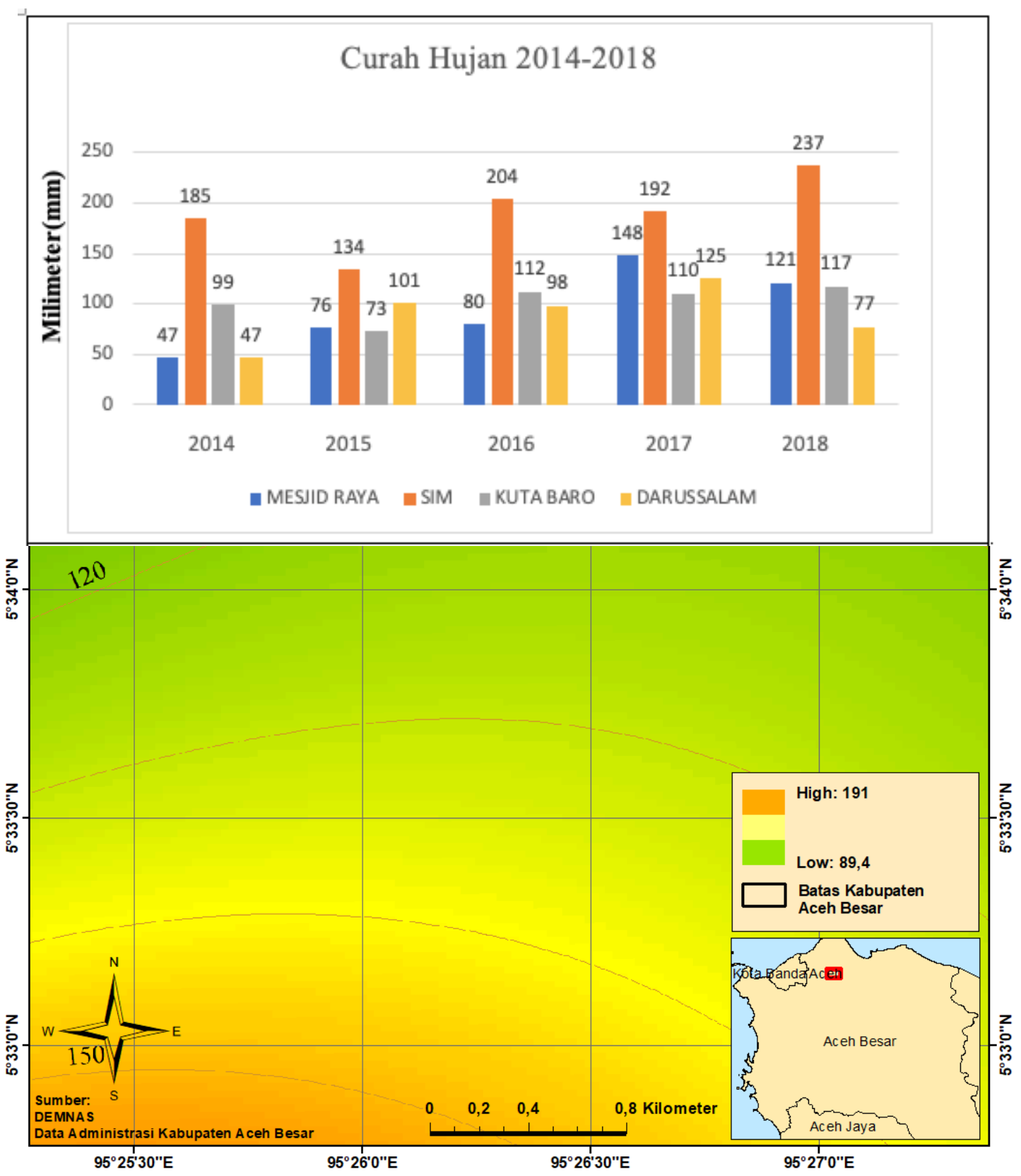

Gambar 6. Peta Curah Hujan dan grafik curah hujan Lokasi Penelitian

Berdasarkan hasil analisis kesesuaian lahan pada lokasi penelitian diperoleh hasil yaitu 3 (tiga) zona evaluasi tataguna lahan pemukiman terdiri dari zona layak, zona kurang layak, dan zona tidak layak. Kelemahan dari setiap zona yang ada berbeda-beda seperti pada zona layak memiliki kemiringan lereng yang datar dan tingkat terjadinya erosi yang kecil. Sedangkan pada zona kurang layak bisa dilihat memiliki kemiringan lereng landai hingga curam, dengan evaluasi tataguna lahannya kurang cocok karena kemiringan lerengnya yang curam sehingga menyebabkan terjadinya erosi yang dapat merusak atau mengubah morfologi tersebut. Zona tidak layak adalah daerah yang memiliki kemiringan lereng yang dari curam hingga sangat curam, dimana potensi untuk terjadinya longsor sangat besar sehingga zona ini tidak layak untuk dijadikan pemukiman. 


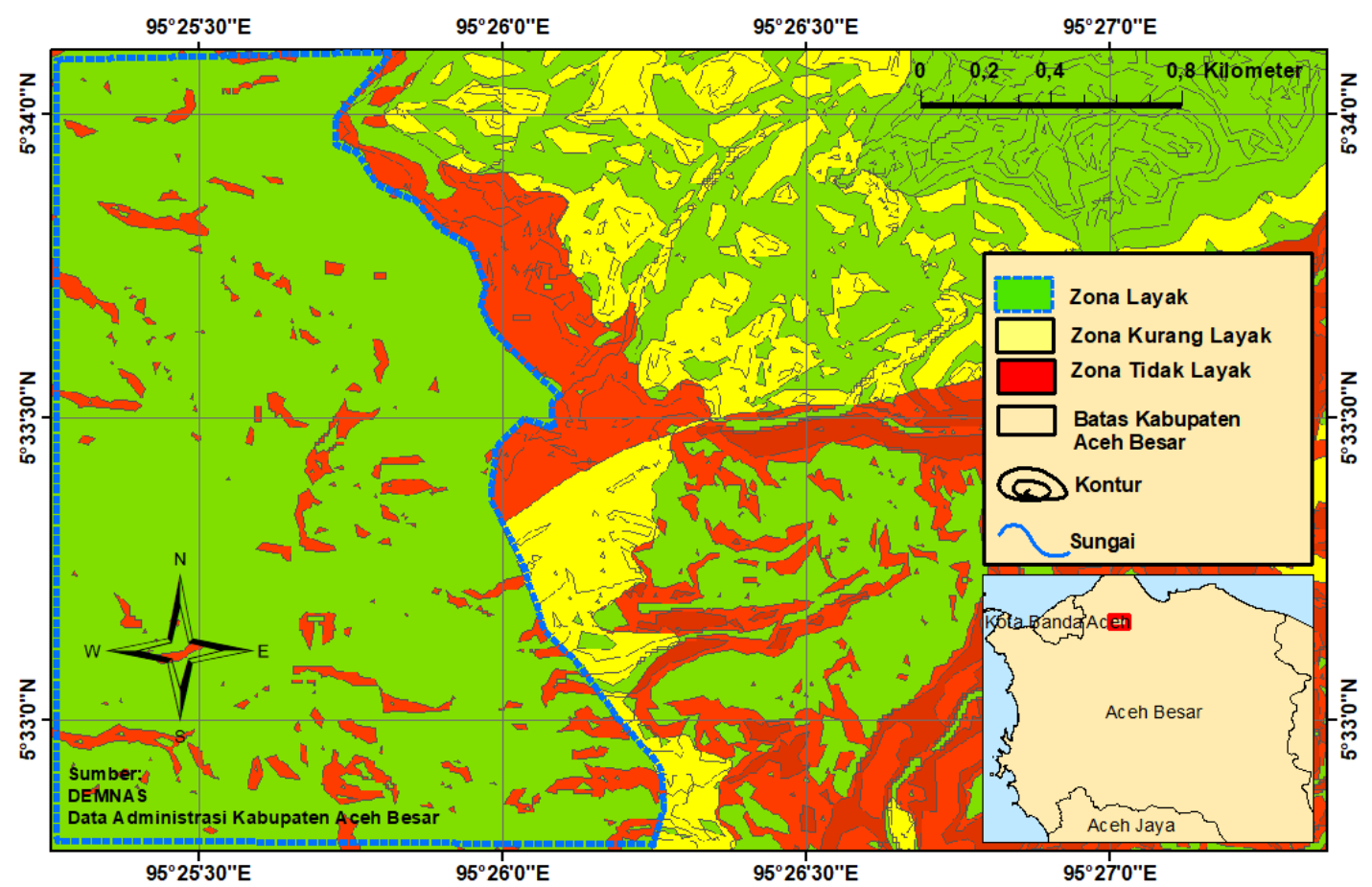

Gambar 7. Peta Kesesuaian Lahan Lokasi Penelitian

Adapun penjelasan kesesuaian lahan pada lokasi penelitian diperoleh hasil 3 (tiga) zona kesesuaian lahan sebagai berikut.

a) Zona layak

Daerah ini dikatakan zona layak karena memiliki kemiringan lereng sekitar $0-8 \%$ dengan topografi datar hingga landai. Tingkat curah hujan pada zona ini lebih tinggi dibandingkan dengan daerah yang ada disekitarnya. Jenis tanah pada daerah ini berupa tanah aluvium yang memiliki tingkat kepekaan terhadap erosi yang sangat rendah.

b) Zona kurang layak

Daerah ini dikatakan zona kurang layak karena memiliki kemiringan lereng sekitar 8 - 25\% dengan topografi landau hingga agak curam. Tingkat curah hujan pada zona ini sangat rendah dan pada daerah ini jenis tanah yang dimiliki berupa tanah litosol yang memiliki tingkat kepekaan terhadap erosi karena tanahnya yang merupakan hasil pelapukan dari batuan tuf. c) Zona tidak layak

Daerah ini dikatakan zona kurang layak karena memiliki kemiringan lereng sekitar 25 - $45 \%$ dengan topografi curam hingga sangat curam. Tingkat curah hujan pada zona ini sangat rendah dan jenis tanah yang terdapat pada daerah ini berupa tanah grumusol yang memiliki tingkat kepekaan terhadap erosi sangat tinggi karena tanahnya yang merupakan hasil pelapukan dari batuan beku.

\section{KESIMPULAN}

Parameter yang digunakan dalam melakukan analisis tataguna lahan yaitu terdiri dari litologi, geomorfologi, kemiringan lereng, jenis tanah dan curah hujan. Berdasarkan hasil analisis kesesuaian lahan pada lokasi penelitian, diperoleh 3 (tiga) zona kesesuaian tataguna lahan pemukiman yaitu zona layak, zona kurang layak dan zona tidak layak. Analisis kesesuaian tataguna lahan berdasarkan zona layak untuk pemukiman pada Kecamatan Kuta Baro yaitu: geomorfologi dataran rendah tingkat kemiringan $0-8 \%$, litologi batuan berupa endapan lanau, curah hujan rendah, serta jenis tanah tanah aluvium yang memiliki tingkat erosi yang sangat rendah.

\section{DAFTAR PUSTAKA}

[1] BPS, Aceh Besar Dalam Angka. Aceh Besar : BPS Kabupaten Aceh Besar, 2018.

[2] Asdak, C. Hidrologi dan Pengelolaan Daerah Aliran Sungai. Yogyakarta : Penerbit Gajah Mada University Press, Bulaksumur, 2001. 
[3] Bates, R.L. dan Jackson, J.A. Glossary of Geology. American Geological Institute, 1987.

[4] BBSDLP (Balai Besar Penelitian dan Pengembangan Sumberdaya Lahan Pertanian). Konsorium Penelitian dan Pengembangan Perubahan Iklim Pada Sektor Pertanian. Balai Besar Penelitian dan Pengembangan Sumberdaya Lahan Pertanian : 2008.

[5] Darmanto. Penerapan Metode AHP (Analytic Hierarchy Process) untuk Menentukan Kualitas Gula Tumbuk. Jurnal SIMETRIS, Vol.5 No 1. ISSN : 2254-4983, 2014.

[6] Saaty, T.L. The Analytic Hierarchy Process. New York: McGraw-Hill, 1980.

[7] Hardjowigeno, S. Klasifikasi Tanah dan Pedogenesis. Jakarta: Akademika Pressindo, 2003.

[8] Bennet, J.D, D.McC, Bridge, N.R, Cameron, A, Djunuddin, S.A, Ghazali, D.H, Jeffery, W, Kartawa, W, Keats, N.M.S, Rock, S.J, Thomson, dan R, Whandoyo. Peta Geologi Lembar Banda Aceh, Sumatera, Skala 1:250.000. Bandung : Pusat Penelitian dan Pengembangan Geologi, 1981.

[9] Bronto, S. Geologi Gunung Api Purba. Bandung: Badan Geologi, 2010.

[10] Bronto, S. Fasies Gunung Api dan Aplikasinya. Jurnal Geologi Indonesia 1 (2): 59-71, 2006.

[11] Van Zuidam, R. A. Aerial Photo - Interpretation in Terrain Analysis and Geomorphologic Mapping. ITC, Smits Publ., Enschede, The Hague, 1985. 